\title{
Biologically Active Gibberellins and Abscisic Acid in Fruit of Two Late-maturing Japanese Pear Cultivars with Contrasting Fruit Size
}

\author{
Caixi Zhang \\ College of Agriculture and Biology, Shanghai Jiaotong University, Shanghai 201101, China; \\ Faculty of Agriculture, Tottori University, Tottori, 680-8533, Japan
}

\author{
Kenji Tanabe ${ }^{1}$, Hiroko Tani, Hiromitsu Nakajima, Minori Mori, and Emi Sakuno \\ Faculty of Agriculture, Tottori University, Tottori, 680-8533, Japan
}

\begin{abstract}
AdDitional INDEX words. ABA, fruit development, GC-MS-SIM, GAs, Pyrus pyrifolia, quantification
Abstract. Both 'Atago' and 'Shinkou' are late-season japanese pear (Pyrus pyrifolia Nakai) cultivars with russetbrown fruit, and the progenies of crosses made between 'Nijisseiki' and unknown cultivars, but they display different growth habit, fruit size, and fruit quality. To clarify the difference in fruit development between the two cultivars, the levels of endogenous gibberellins $\left(\mathrm{GA}_{1}, \mathbf{G A}_{3}\right.$, and $\left.\mathbf{G A}_{4}\right)$ and abscisic acid $(\mathrm{ABA})$ in fruit were identified and quantified by gas chromatography/mass spectrometry, and a histological study of fruit was carried out. The results showed that cell number rather than cell size of mesocarp is responsible for the difference in fruit size between the two cultivars. Furthermore, analysis of endogenous bioactive gibberellins revealed that 'Atago' fruit has much higher levels of $\mathrm{GA}_{1}$, $\mathrm{GA}_{3}$, and $\mathrm{GA}_{4}$ than 'Shinkou' fruit during fruit development, particularly during the early period of fruit growth. However, 'Shinkou' has a much higher ABA level than 'Atago' during the early period of fruit development. Abscisic acid concentration remained at an extremely low level after the first production peak after anthesis in 'Atago' compared with 'Shinkou'.
\end{abstract}

Gibberellins form a group of more than 130 tetracyclic diterpenes, some of which are biologically active, such as gibberellic acid $1\left(\mathrm{GA}_{1}\right), \mathrm{GA}_{3}, \mathrm{GA}_{4}$, and $\mathrm{GA}_{7}$, and act as endogenous regulators of plant growth and development (Davies, 2004). Work on GA-deficient mutants has established that bioactive GAs are involved in many aspects of plant development, including seed germination, trichome development, stem and leaf elongation, flower induction, anther development, and fruit and seed development (Hedden and Phillips, 2000). Moreover, abscisic acid (ABA) exerts antagonistic effects on the GA-regulated process and is necessary for seed development (Davies, 2004). Generally, fruit development is dependent on the interactions of five major classes of plant hormones (auxin, GAs, cytokinin, ABA, and ethylene) and GAs play a major role in this process (Pharis and King, 1985), inducing fruit set and expansion of the pericarp, and, as a consequence, they have important practical applications in fruit production. For example, exogenous GAs have been applied to increase fruit enlargement in grape (Vitis L.) and japanese pear, and to enhance fruit set in seedless cultivars of mandarin (Citrus reticulata L.) (Hayashi and Tanabe, 1991; Zhang et al., 2005c).

It is well known that fruit growth of japanese pear is characterized by an initial period of rapid cell division, followed by a long period of cell expansion, primarily by

Received for publication 12 Oct. 2006. Accepted for publication 18 Apr. 2007. This work was supported by the Japanese Society of the Promotion of Science (no. P06196).

We thank Kumiko Okayama and Ryo Aoki for their invaluable help in gibberellic acid analysis.

${ }^{1}$ Corresponding author. E-mail: tanabe@muses.tottori-u.ac.jp. vacuolation (Hayashi and Tanabe, 1991). Many studies have focused on the two stages and concluded that cell number and cell size are very important for determining final fruit size (Zhang et al., 2005a, b, c, 2006). Therefore, knowledge of factors that affect the two stages would be particularly helpful to understand the regulation of fruit size in higher plants. In japanese pear, it has been suggested that GAs are closely involved in fruit development (Hayashi and Tanabe, 1991; Nakagawa et al., 1973; Yuda et al., 1981, 1984). In addition to the effect of GA in maintaining cell expansion (Ozga and Dennis, 2003; Zhang et al., 2005c), the fact that the application of GAs during the early period of fruit development result in a larger fruit also indicate that GAs might play a role in cell division in pear fruit. Recently, GAs derived from cotyledons have been shown to play a role in cell division during tissue reunion in the cortex of hypocotyls in cucumber (Cucumis sativus L.) and tomato (Lycopersicon esculentum Mill.), which also confirmed the role of GAs in cell division (Asahina et al., 2002).

In a previous report, it was determined that both 'Atago' and 'Shinkou' are late-season cultivars with russet-brown fruit (Fig. 1), and the progenies of crosses made between 'Nijisseiki' and unknown cultivars in Japan, but they display different growth habits, architectural traits, and fruit growth rate (Zhang et al., 2005b). Fruit of 'Atago' are harvested in early November and trees are spur type, moderately vigorous, and productive. It is notable for having the largest fruit among japanese pears, weighing as much as 1500 to $2000 \mathrm{~g}$. 'Shinkou,' with mediumto large-size fruit (400-500 g), is harvested 2 to 3 weeks earlier than 'Atago'. Trees of this cultivar are usually moderately vigorous with a heavily spurred habit during the early years after planting and are subsequently characterized by weak 


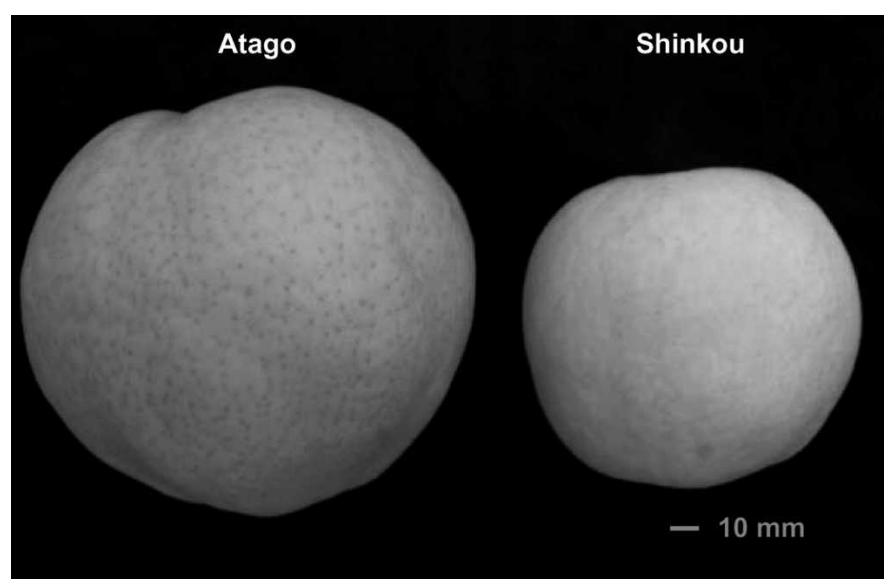

Fig. 1. Fruit of two late-maturing japanese pear cultivars: Atago (left, $1500 \mathrm{~g}$ ) and Shinkou (right, $500 \mathrm{~g}$ ).

growth. Previous work has suggested that the difference in fruit size between the two cultivars was the result of sink strength of fruit (Zhang et al., 2005b), and further studies indicated that GAs are closely related to enhancement of sink demand in japanese pear (Zhang et al., 2005c, 2007).

Identification and quantification of GAs should be useful for elucidating the physiological mechanism and exact roles of endogenous GAs and ABA in pear fruit development, because most of the processes involved in GAs during fruit development are triggered by reactive GAs. Therefore, this study focused primarily on the bioactive GAs. Although bioactive GA-like substances were found in pear seeds, only $\mathrm{GA}_{3}$ has been identified (Nakagawa et al., 1979; Yuda et al., 1983). Additionally, preliminary analyses of GAs by bioassay suggested dramatic quantitative changes during pear fruit development (Hayashi and Tanabe, 1991). However, there is no information about the absolute quantity of bioactive GAs and the difference in GA concentrations between cultivars. A gas chromatographymass spectrometry (GC-MS) approach provides more reliable identifications and more complete quantitative analysis than bioassays. Therefore, the main purpose of this work was to determine endogenous hormones levels (bioactive GAs and ABA) in developing fruit of japanese pear cultivars, Atago and Shinkou, while contrasting fruit size and the patterns of fruit growth (cell division/cell enlargement) to obtain information for evaluating the roles of GAs and ABA involved in fruit growth.

\section{Materials and Methods}

Plant materials and fruit growth. Seven 12-year-old japanese pear trees with uniform vigor from both cultivars, Atago and Shinkou, grafted onto Pyrus betulaefolia Bunge rootstocks were selected for experiments. Trees were spaced $4 \times 5 \mathrm{~m}$ apart and were trained to a flat-canopied, pergola system. All classes of scaffolds and lateral branches were tied to a horizontal trellis (Zhang et al., 2005b). Cultural management practices, such as fertilization, pruning, pest control, and thinning, were the same as those used in a commercial orchard. Flowers were hand pollinated with pollen of 'Chojuro' pear during full bloom, and the flowers were collected $5 \mathrm{~h}$ after pollination for GA analysis [0 d after anthesis (DAA)]. Each spur was hand thinned to one fruit 4 weeks after anthesis. The crop loads for the two cultivars were maintained at 0.8 to
1.5 fruit $/ \mathrm{cm}^{2}$ of trunk cross-sectional area. The fruit (or flowers) were collected randomly at $0,4,7,12,22,32,42,52,62,72,87$, $102,117,137,157,177$, and 210 DAA for measurement of fresh fruit weight, histological examination of fruit, and GA analysis. Immediately after collection, the samples were frozen in liquid $\mathrm{N}_{2}$ and kept in sealed plastic bags at $-80{ }^{\circ} \mathrm{C}$ until analyzed.

SEED GROWTH AND histological OBSERVATION OF FRUIT. The seeds of both cultivars were collected from four fruit, respectively, on each sampling date and the seed length, width, and thickness and fresh weight were measured. At the same time, the growth pattern of the endosperm and the embryo was also investigated. For histological observation of fruit, 15 fruit/ cultivar were collected and immediately preserved in formalinacetic-alcohol (90 ethanol : 5 acetic acid : 5 formalin $80 \%$ ). The measurement of cell number and cell length of the mesocarp was measured as described by Zhang et al. (2005a). First, the fruit collected after $22 \mathrm{DAA}$ were cut along the equatorial region (Fig. 2). Then, mesocarp width was calculated from the difference between the longest width of the transverse section of fruit and core. Subsequently, the mesocarp was sliced along the equatorial region and stained by rubbing it softly with a cloth soaked in blue ink. The stained surface was observed under a digital high-frequency microscope system (VH-8000; Keyence, Tokyo), and an image from a charge-coupled device camera was displayed on a monitor. Cell length, as an indicator of cell size, was measured from the length of seven contiguous cells from the core to the fruit surface, and the average cell length was calculated. Ten observation zones per section were
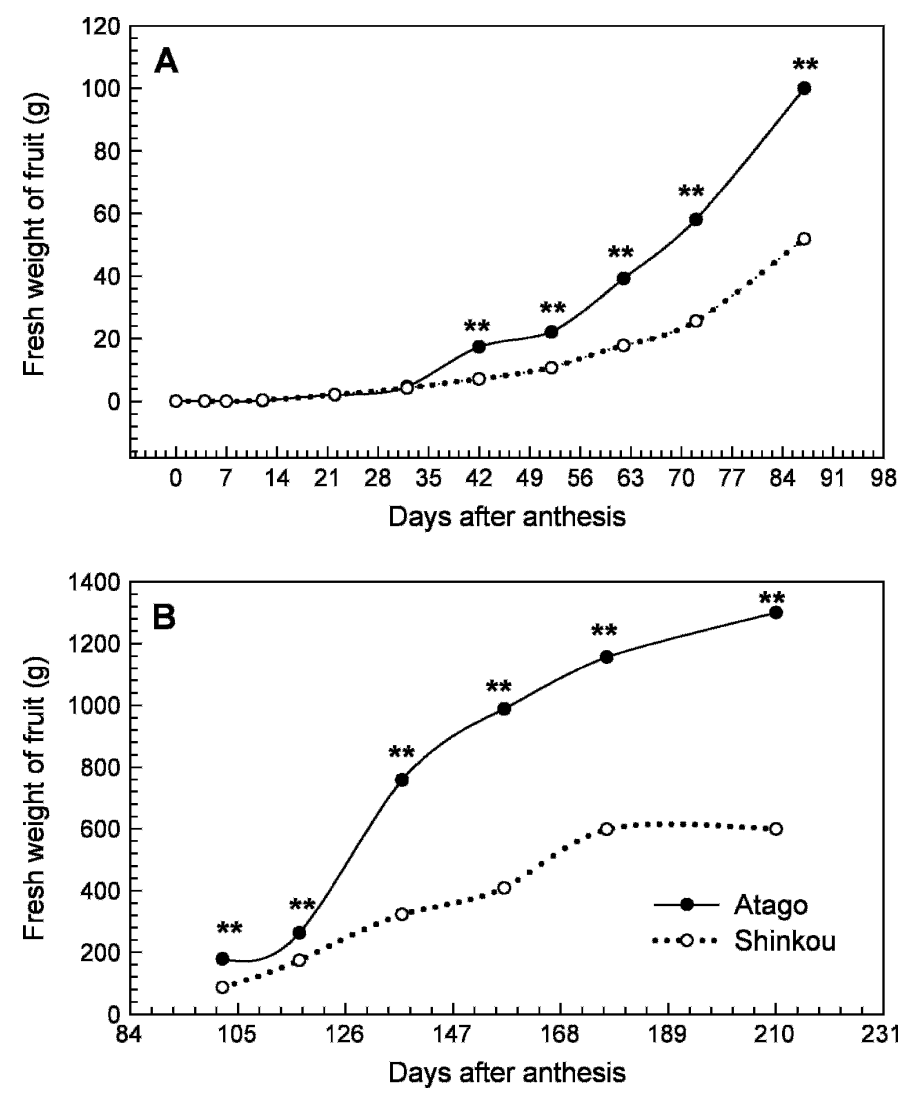

Fig. 2. (A, B) Patterns of fruit fresh weight during fruit development in two latematuring japanese pear cultivars, Atago and Shinkou: 0 to $87 \mathrm{~d}$ after anthesis (A) and 0 to $214 \mathrm{~d}$ after anthesis (B). ${ }^{* *}$ Significant at $P<0.01 ; \mathrm{N}=7$. 
measured. Cell number of mesocarp along the equatorial region was then calculated by dividing the mesocarp width by average cell length, which was an indicator of total cell number per fruit. The fruit (or flowers) collected from 0 to 22 DAA were too small to observe with digital calipers, so the mesocarp width was also measured under microscope, and cell number and cell length of the mesocarp was recorded.

DETERMINATION OF PERIOD OF CELL DIVISION. In a previous study with japanese pear, it has been suggested that the duration of cell division was cultivar dependent in japanese pear (Zhang et al., 2005a, 2006). Therefore, to estimate the duration of cell division, the increasing patterns of cell number of the mesocarp in both cultivars were fitted by logarithmic curves. The critical point where the slope of the fitted curve was less than 0.5 cells/d was calculated according to Zhang et al. (2005a), and the period from pollination to the critical point was regarded as the period of cell division for each cultivar.

Gibberellic acid Extraction. The frozen fruit were homogenized and extracted overnight in $80 \%$ cold aqueous methanol containing $0.02 \%$ butyl hydroxytoluene. At this point, $100 \mathrm{ng}$ deuterated GAs $\left\{\left[17-{ }^{2} \mathrm{H}_{2}\right] \mathrm{GA}_{1},\left[17-{ }^{2} \mathrm{H}_{2}\right] \mathrm{GA}_{3}\right.$ and $\left.\left[17-{ }^{2} \mathrm{H}_{2}\right] \mathrm{GA}_{4}\right\}$ and $100 \mathrm{ng}{ }^{13} \mathrm{C}$-ABA were included in the samples as internal standards for recovery estimation after purification. The solution was then filtered and the residue was reextracted twice with $80 \%$ cold aqueous methanol. After filtration, the pooled extracts were evaporated in vacuo at $42{ }^{\circ} \mathrm{C}$ to an aqueous solution. The aqueous residue was adjusted to a pH of 6 to 7 and was partitioned against hexane three times. The pooled aqueous residue was then adjusted to $\mathrm{pH} 2.5$ with $\mathrm{HCl}$ and partitioned against ethyl acetate. The pooled ethyl acetate phase was partitioned against a potassium phosphate buffer ( $\mathrm{pH}, 8.0)$. Then, insoluble polyvinylpolypyrrolidone was added to the combined aqueous solution and filtered. The filtered aqueous solution was adjusted to $\mathrm{pH} 2.5$ with $\mathrm{HCl}$ and partitioned against ethyl acetate again. The pooled ethyl acetate solution was dried over $\mathrm{Na}_{2} \mathrm{SO}_{4}$ and evaporated in vacuo. The residue was dissolved in a small amount of $80 \%$ aqueous methanol, and loaded onto a C18 Presep-Cartridge (Wako Pure Chemical Industries, Ltd., Osaka, Japan), which had been prewetted with water, $100 \%$ and $80 \%$ methanol, followed by drying in vacuo. The residue was dissolved in a small amount of $45 \%$ methanol-water containing $0.1 \%$ acetic acid and further loaded onto a Bondesil DEA (diethylaminopropyl) column (Varian Associates, Palo Alto, CA). The sample was eluted in succession with distilled water and methanol. The elute was evaporated in vacuo and stored at $-20{ }^{\circ} \mathrm{C}$ for further purification by high-performance liquid chromatography (HPLC).

High-PERFORMANCE LIQUID CHROMATOGRAPHY. The residue was subjected to a reverse-phase Senshu-Pak ODS(OctaDecylSilyl)-4253-D HPLC column (10 mm i.d. $\times 250 \mathrm{~mm}$; Senshu Scientific, Tokyo) and eluted with $0.1 \%$ acetic acid in $30 \%$ aqueous methanol (solvent $\mathrm{A}$ ) and 100\% aqueous methanol (solvent B) at $40{ }^{\circ} \mathrm{C}$ as follows: 0 to $3 \mathrm{~min}$, elution with solvent A; 3 to $30 \mathrm{~min}$, linear gradient of $0 \%$ to $100 \%$ solvent $\mathrm{B} ; 30$ to 50 min, elution with $100 \%$ solvent $\mathrm{B}$. The flow rate of the solvent was $3 \mathrm{~mL} \cdot \mathrm{min}^{-1}$, and the eluate was collected every $1 \mathrm{~min}$ as one fraction. The retention times of $\mathrm{ABA}, \mathrm{GA}_{1}, \mathrm{GA}_{3}$, and $\mathrm{GA}_{4}$ were identified by running authentic standards under the same conditions. The bioactivity for GAs was detected with the microdrop method using a dwarf rice (Oryza sativa L.) cv. Tan-ginbozu seedling test (Nishijima and Katsura, 1989). The retention times of $\mathrm{ABA}, \mathrm{GA}_{1}, \mathrm{GA}_{3}$, and $\mathrm{GA}_{4}$ were 18 to $19 \mathrm{~min}$, $16 \mathrm{~min}, 14$ to $15 \mathrm{~min}$, and 26 to $28 \mathrm{~min}$ respectively.

GAS CHROMATOGRAPHY-MASS SPECTROMETRY-SELECTED ION Monitoring. The bioactive GA-like fractions from the fruit were dissolved in $100 \%$ methanol, transferred to a reaction vial, and dried at room temperature. The samples were then dissolved in $100 \%$ methanol and methylated with ethereal diazomethane followed by trimethylsilylation with N-methyl$\mathrm{N}$-(trimethysilyl)-trifluoroacetamide $(10 \mu \mathrm{L}$; Sigma, St. Louis) in glass vial at $80^{\circ} \mathrm{C}$ for GC-MS (6890N network GC system; Agilent Technologies Santa Clara, CA) analysis. One microliter of each silylated sample was injected into a DB-1 fusedsilica chemically bonded capillary column $[15 \mathrm{~m}, 0.25 \mathrm{~mm}$ (i.d.), 0.25- $\mu \mathrm{m}$ film thickness; Agilent Technologies]. The GC oven temperature for GAs was programmed for $3 \mathrm{~min}$, held at $80{ }^{\circ} \mathrm{C}$, then increased at $15^{\circ} \mathrm{C} \cdot \mathrm{min}^{-1}$ to $300{ }^{\circ} \mathrm{C}$, followed by 5 min at $300{ }^{\circ} \mathrm{C}$. Helium carrier gas was maintained at a head pressure of $30 \mathrm{kPa}$. The $\mathrm{GC}$ was directly interfaced with a mass selective detector with an interface and source temperature of $280^{\circ} \mathrm{C}$, an ionizing voltage of $70 \mathrm{eV}$, and a dwell time of $100 \mathrm{~ms}$.

A portion of ABA equivalent fraction from ODS-HPLC was subjected to $\mathrm{GC}$-mass spectrometry-selected ion monitoring (SIM) analysis after methylation with ethereal diazomethane. The GC conditions were as follows: 3 min held at $60{ }^{\circ} \mathrm{C}$, then increased at $20{ }^{\circ} \mathrm{C} \cdot \mathrm{min}^{-1}$ to $290{ }^{\circ} \mathrm{C}$, and maintained at $290{ }^{\circ} \mathrm{C}$ for $5 \mathrm{~min}$.

QUANTIFICATION OF BIOLOGICALLY ACTIVE ENDOGENOUS GAS AND ABSCISIC ACID. The identity of eluted GAs, according to retention times, was verified by monitoring diagnostic ions of both endogenous GAs and deuterated GAs. Levels of endogenous GAs were determined by measuring the abundance of the following ion pairs: m/z 506/508 for $\mathrm{GA}_{1}, \mathrm{~m} / \mathrm{z}$ 504/506 for $\mathrm{GA}_{3}$, and both $\mathrm{m} / \mathrm{z} 418 / 420$ and $284 / 286$ for $\mathrm{GA}_{4}$. In the GCSIM analysis of ABA, characteristic ions m/z 190/192 were monitored.

Statistical analysis. Statistical differences between treatments were analyzed by Student's $t$ test using SigmaPlot v. 9.0 (Jandel Scientific, San Rafael, CA) software. A probability of $P>0.05$ was considered nonsignificant.

\section{Results}

Fresh FRUit WEIGHT, CELL Division/ENLARGEMENT, AND SEED GROWTH. Seasonal fruit development in both cultivars followed a single sigmoid growth curve based on the measurement of fresh weight (Fig. 2). Fruit of 'Atago' entered the rapid fruit growth stage earlier than those of 'Shinkou' (Fig. 2A). On the other hand, 'Shinkou' displayed a shorter period of fruit enlargement, longer maturation stage, and more moderate slope of growth curve during the linear stage than 'Atago' (Fig. 2B).

The period of cell division in 'Atago' and 'Shinkou' was $\approx 46$ and $61 \mathrm{~d}$ respectively (Fig. 3B). At 0 DAA (full bloom), 'Atago' had fewer cells in the fruit than 'Shinkou'; however, 1 week later, 'Shinkou' had more cells in the mesocarp. In particular, the cell number of the mesocarp in 'Atago' increased sharply (Fig. 3A), and the final cell number of the mesocarp in 'Atago' was $\approx 3.6$ times more than that in 'Shinkou' (Fig. 3B). However, 'Shinkou' had larger cells than 'Atago' (Fig. 3C). Moreover, although 'Shinkou' has a smaller fruit than 'Atago', there was a nonsignificant difference in core diameter between the two cultivars (Figs. 2 and 3D). 

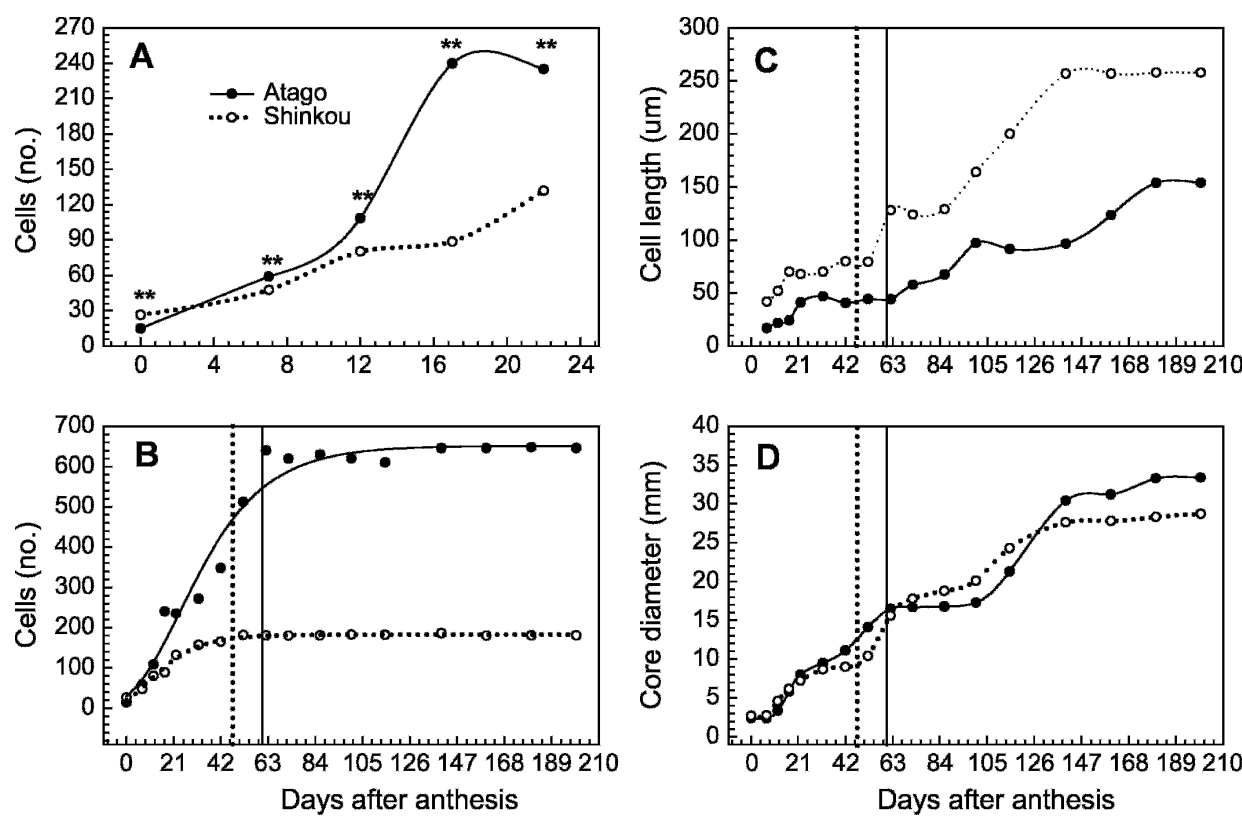

Fig. 3. (A-D) Changes in cell number [0-22 d after anthesis (A) and 0 to $214 \mathrm{~d}$ after anthesis (B) , cell length (C) of the mesocarp along the equatorial region, and core diameter (D) during fruit development in two late-maturing japanese pear cultivars. The patterns of increasing cell number $(\mathbf{B})$ were fitted by the logarithmic curve: 'Atago', $\mathrm{y}=651 \times \exp (-\exp [-(\mathrm{x}-23.77) / 21.14])$; 'Shinkou', $\mathrm{y}=182.4 \times \exp (-\exp [-(\mathrm{x}-10.11) / 12.65])$. The duration of cell division is indicated by a solid and dotted line respectively (B). **Significant at $P<0.01 ; \mathrm{N}=15$.

In both cultivars, seed length, seed width, and seed thickness increased rapidly after anthesis, which was characterized by endosperm growth, and remained stable after cessation of cell division (Fig. 4A-C). Seed weight increased slowly around the entry to fruit enlargement, and then increased sharply in both cultivars, which mainly resulted from rapid embryo growth (Fig. 4D).

Changes of Endogenous biologically aCtive GibBerellid ACIDS AND ABSCISIC ACID. Generally, endogenous $\mathrm{GA}_{1}, \mathrm{GA}_{3}$, and $\mathrm{GA}_{4}$ levels followed a similar curve in the two cultivars (Fig. 5). In 'Atago', $\mathrm{GA}_{1}, \mathrm{GA}_{3}$, and $\mathrm{GA}_{4}$ levels were highest at 4 DAA, and declined rapidly thereafter. However, significantly lower $\mathrm{GA}_{1}, \mathrm{GA}_{3}$, and $\mathrm{GA}_{4}$ levels were measured after anthesis. The first peak in GA levels was detected at 7, 12, and 0 DAA for $\mathrm{GA}_{1}, \mathrm{GA}_{3}$, and $\mathrm{GA}_{4}$, respectively, in 'Shinkou'. The highest $\mathrm{GA}_{3}$ level was more than $\mathrm{GA}_{1}$ and $\mathrm{GA}_{4}$ levels in both cultivars. Subsequently, a second bioactive GA peak was measured after the first peak, but the $\mathrm{GA}_{3}$ peak appeared later than that of $\mathrm{GA}_{1}$, and the second $\mathrm{GA}_{4}$ peak occurred around the time when cell division ceased in both cultivars. The occurrence of the second peaks of $\mathrm{GA}_{3}$ and $\mathrm{GA}_{4}$ in 'Atago' was later than those in 'Shinkou', and their GA levels in 'Atago' were also more than that in 'Shinkou.' However, the second peak of GA 1 in 'Atago' occurred earlier than that in 'Shinkou', and there was no difference in $\mathrm{GA}_{1}$ levels between cultivars.

During rapid fruit development, there was no difference in $\mathrm{GA}_{1}$ level between cultivars (Fig. 5A). The third peaks of $\mathrm{GA}_{3}$ occurred earlier than $\mathrm{GA}_{4}$, and both the third peaks of $\mathrm{GA}_{3}$ and $\mathrm{GA}_{4}$ in 'Shinkou' also occurred earlier and were smaller than those for 'Atago'. The total amount of bioactive GAs followed a similar curve as the single bioactive GA, and generally 'Atago' had higher bioactive GA levels than 'Shinkou'.

The ABA levels peaked after anthesis and remained at a high level thereafter in both cultivars (Fig. 6). However, the ABA concentration remained at a very low level after the first peak after anthesis in 'Atago' compared with 'Shinkou'. During the period of cell division, the ABA concentration in 'Shinkou' remained higher than that of 'Atago'. Although the ABA level decreased when cell enlargement began, it still remained at a relatively high level in 'Shinkou' fruit than in 'Atago' fruit.

\section{Discussion}

Gibberellic acid biosynthetic pathways are of considerably complexity in plants (Davies, 2004). They are divided into an early nonhydroxylation pathway, in which $\mathrm{GA}_{4}$ is produced, and an early 13hydroxylation pathway, in which $\mathrm{GA}_{1}$ and $\mathrm{GA}_{3}$ are produced. Although bioactive GA-like substances were found in pear seeds, only $\mathrm{GA}_{3}$ has been identified in the immature seeds by GC-MS (Yuda et al., 1983). In this study, $\mathrm{GA}_{1}$, $\mathrm{GA}_{3}$, and $\mathrm{GA}_{4}$ were successfully identified (Fig. 5), suggesting that both the early nonhydroxylation and early 13-hydroxylation pathway might function during fruit development in japanese pear.

Fruit SET, CELl division, AND GibBerellic ACID. It is well known that successful fruit set and subsequent development in seeded plants are dependent on pollination and fertilization, because fertilization activates cell division and triggers fruit growth by producing hormones, principally GAs and auxins (Crane, 1964; Hedden and Hoad, 1985). Gibberellic acids, for example, are actively involved in this process in citrus $(C$. reticulata) and apple (Malus $\times$ domestica Borkh.) (Ben-Cheikh et al., 1997; Hedden and Hoad, 1985; Talon et al., 1990). In pea (Pisum sativum L.), it appears that $\mathrm{GA}_{1}$ or $\mathrm{GA}_{3}$ are the active GAs that induce fruit set and pericarp growth. The concentrations of $\mathrm{GA}_{1}$ and $\mathrm{GA}_{3}$ were highest at the time of most rapid pod growth rate (4-7 DAA), but present in trace or undetectable amounts in unpollinated ovaries and in parthenocarpic fruit growing in the absence of pollination (GarciaMartinez and Hedden, 1997). Similarly, the bioactive GA levels of pear fruit peaked after the onset of anthesis and then declined rapidly (Fig. 5). The concurrent occurrence of $\mathrm{GA}_{1}$, $\mathrm{GA}_{3}$, and $\mathrm{GA}_{4}$ in the developing fruit raises the question of whether all of them, or only one of them, are involved in the regulation of fruit development. Quantitative differences between cultivars in $\mathrm{GA}_{1}, \mathrm{GA}_{3}$, and $\mathrm{GA}_{4}$ levels were detected (Fig. $5 \mathrm{~A}-\mathrm{C}$ ), and the results indicated that $\mathrm{GA}_{1}$ and $\mathrm{GA}_{3}$, rather than $\mathrm{GA}_{4}$, are more related to fruit set in japanese pear. Although it has been reported that $\mathrm{GA}_{3}$ did not induce parthenocarpy in japanese pear (Yuda et al., 1983), $\mathrm{GA}_{3}$ in pear could delay in embryo sac degeneration, resulting in an extended period of ovule receptivity and an increased probability of successful fertilization under suboptimal pollination conditions (Herrero and Gascon, 1987). Our unpublished data also suggested that $\mathrm{GA}_{3}$ is closely involved 

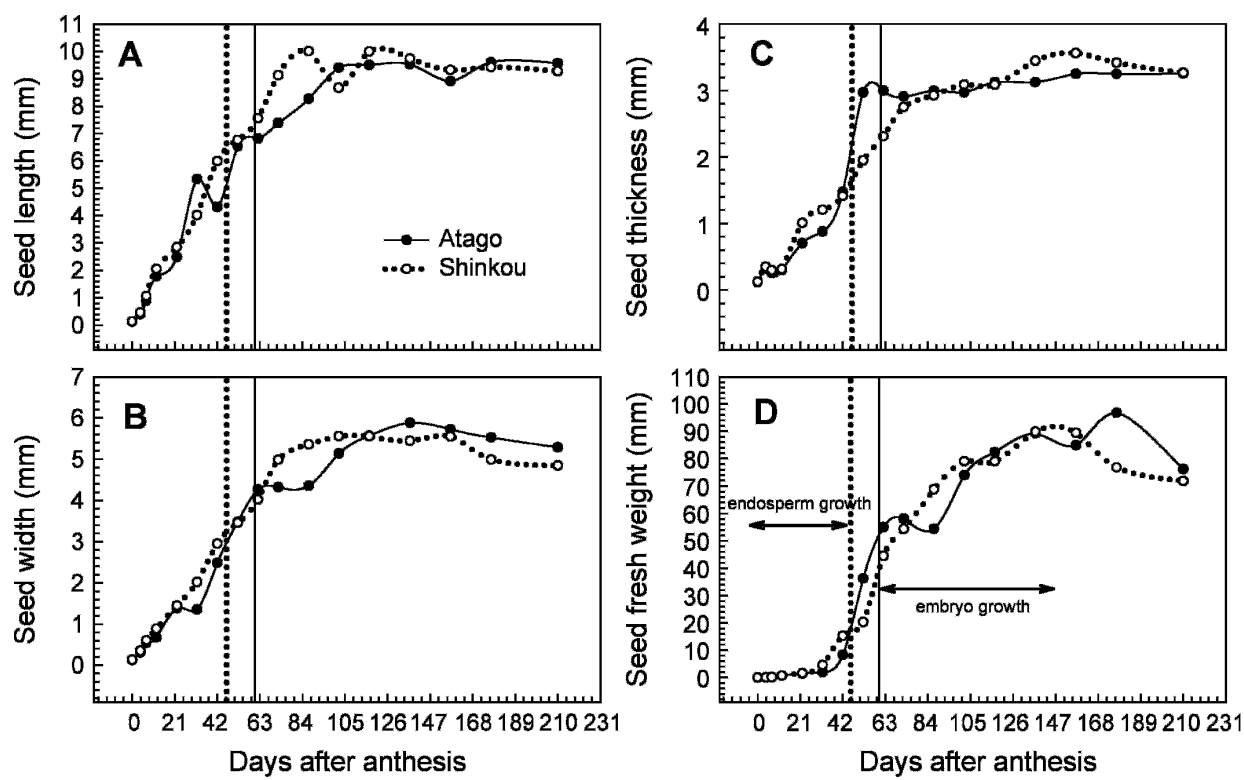

Fig. 4. (A-D) Changes in the length (A), width (B), thickness (C), and fresh weight (D) of seeds in two latematuring japanese pear cultivars, Atago and Shinkou. $\mathrm{N}=4$.
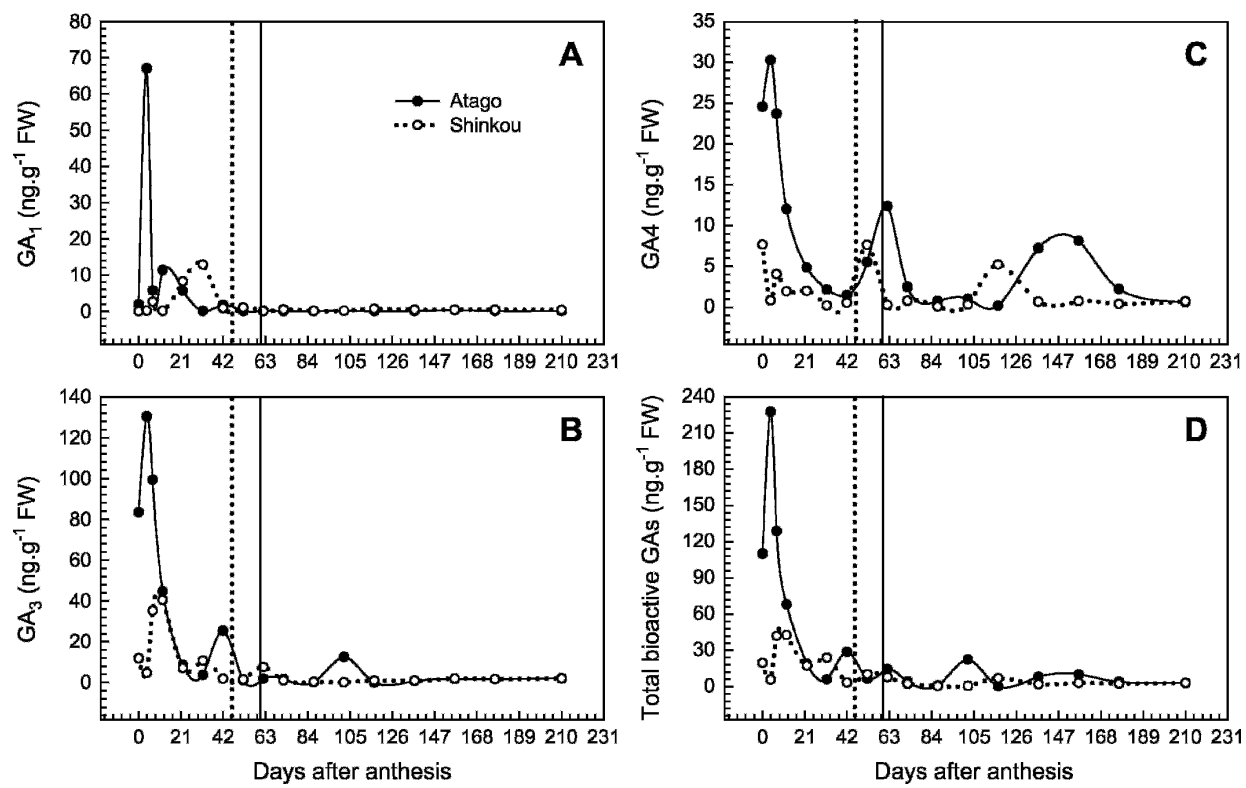

Fig. 5. (A-D) Changes in endogenous gibberellic acid $1\left(\mathrm{GA}_{1}\right)(\mathbf{A}), \mathrm{GA}_{3}(\mathbf{B}), \mathrm{GA}_{4}(\mathbf{C})$, and total bioactive GAs (D) levels in fruit of two late-maturing japanese pear cultivars, Atago and Shinkou. FW, fresh weight. significantly higher bioactive GAs levels than 'Shinkou', and the fact that a dramatic increase in cell division and a significantly higher cell number in the mesocarp in the former than in the latter also suggested the involvement of GAs in this process. Cell division of fruit is crucial for the difference in final fruit size between cultivars (Zhang et al., 2005a, 2006).

The developing young seeds are an important source of GAs (GarciaMartinez and Hedden, 1997; Hayashi and Tanabe, 1991). It also has been suggested that GAs produced in the developing anthers are required for corolla development (Weiss et al., 1997). Gibberellic acid deficiency led to male sterility as a result of abnormal anther development in arabidopsis [Arabidopsis thaliana (L.) Heynh.] and tomato (Goto and Pharis, 1999; Nester and Zeevaart, 1988). In addition, GAs also are present in developing pollen after anthesis (Barendse et al., 1970; Mander et al., 1996), because GAs are required for normal pollen tube growth (Singh et al., 2002). Interestingly, it has been reported that de novo GA biosynthesis occurs in pollen tubes after germination (Singh et al., 2002). During hand pollination, fruit growth of japanese pear was strongly activated by increasing the pollen number on the stigma, which led to the enhancement of cell division and a larger fruit (Hayashi and Tanabe, 1991). The overall GA concentrations increased dramatically immediately after anthesis in the current study, strongly indicating that the production of GAs might be closely involved with the processes of pollination and fertilization.

In fruit, GAs tend to be concentrated in seeds, changing in kind and quantity as endosperm and embryo development proceed (Morris, 1997;

in fruit set by using bioactive GAs combined with selective inhibitors at anthesis.

It is well known that the major role of GAs in fruit growth is the promotion of cell expansion (Garcia-Martinez and Hedden, 1997). On the other hand, there is some indication that GAs also play a role in cell division (Asahina et al., 2002). The effect of exogenous application of GAs and its inhibitors during early fruit growth in both cultivars showed that GAs could significantly increase cell division, and resulted in a larger fruit (unpublished data). It is apparent that GAs were closely involved in the process of cell division in pear fruit (Figs. 2 and 5). During the period of cell division, 'Atago' had
Swain et al., 1997). In this study, the second and third phase of GA production corresponded to the development of the embryo and the endosperm respectively (Fig. 3). The rapid growth of seed during cell division was the result of the development of the embryo and the endosperm, and a sharp increase in fresh weight of seed resulted mainly from the growth of embryo. Additionally, there is considerable evidence to suggest that seed-derived GAs are necessary for normal fruit development in many species, and GAs are produced close to or at the site of action (Sponel and Hedden, 2004). However, in some cases the seeds may stimulate the pericarp to synthesize biologically active GAs for their own growth, rather than to promote fruit 


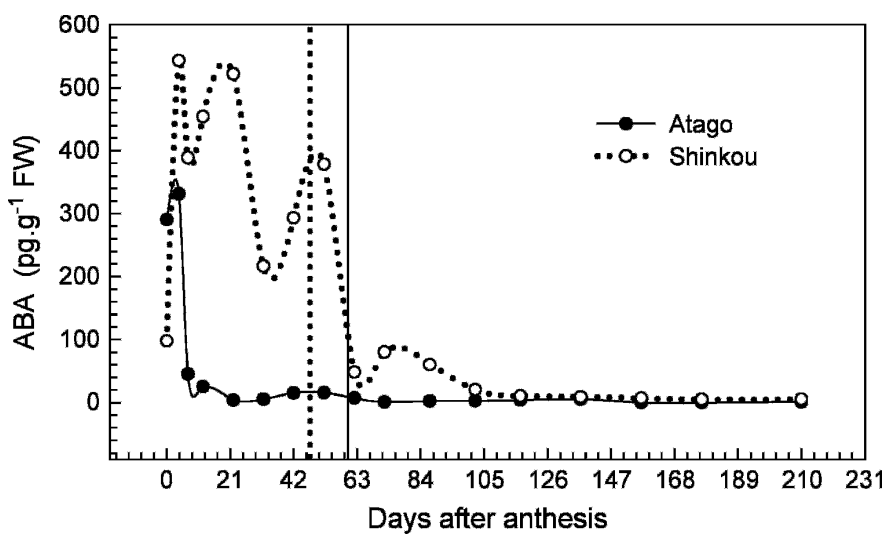

Fig. 6. Changes in endogenous abscisic acid (ABA) level in fruit of two latematuring japanese pear cultivars, Atago and Shinkou. Data were recorded on a fresh weight $(\mathrm{FW})$ basis.

expansion (Garcia-Martinez and Hedden, 1997). A large number of studies have found evidence that GA biosynthesis is finely modulated via regulation of the GA dioxygenases. Hisatomi (2003) pointed out that GA biosynthesis mainly exists in seeds during fruit development by investigating the expression of GA-biosynthetic genes.

Cell enlargement and gibberellic aCID. During rapid fruit growth, a third phase of active GA production was observed in japanese pear (Fig. 5). It has been suggested that GAs are effective in maintaining cell expansion (Gillaspy et al., 1993; Ozga and Dennis, 2003); therefore, the application of bioactive GAs during the early period of cell expansion could significantly increase the final fruit size in japanese pear (Hayashi and Tanabe, 1991; Zhang et al., 2005c, 2007). Moreover, we found that $\mathrm{GA}_{3}+4$ increased sink demand by the enhancement of phloem unloading or/and metabolism of carbon assimilates in pear fruit (Zhang et al., 2005c, 2007). Therefore, the third phase of $\mathrm{GA}_{3}+4$ production should be closely related with fruit expansion and the achievement of sink strength of fruit. In a previous report, the analysis of sink strength showed that 'Atago' exhibited greater relative sink strength than 'Shinkou' (Zhang et al., 2005b). Therefore, a higher bioactive GA level during fruit development (Fig. 5) was consistent with the results of the analysis of sink strength and carbon partitioning between the two cultivars (Zhang et al., 2005b).

Abscisic ACID AND fruit Development. Abscisic acid is necessary for seed development, adaptation to several abiotic stresses, and sugar sensing (Davies, 2004). Generally, ABA is involved in embryo maturation in seeds, and elevated ABA levels during mid embryogenesis are necessary for the expression of genes required for the accumulation of storage reserves and tolerance to desiccation. However, the exact roles of ABA in fruit development remain obscure. Yang et al. (2003) pointed out that $\mathrm{ABA}$ content in rice grains was negatively correlated with the cell division rate during the active division period of endosperm cells. In the current study, a higher ABA level was correlated with low cell division in 'Shinkou' compared with 'Atago' during the early period of fruit growth. It is well known that ABA exerts antagonistic effects on GA-regulated processes. In the pathway of isoprenoid biosynthesis, the pathway in plastids branches in several directions at geranylgeranyl diphosphate (GGPP), with separate pathways leading to the ent-kaurenoids and GAs, the phytyl side chain chlorophyll, phytoene, and carotenoids (the precursor of ABA), and the nonaprenyl side chain of plastoquinone (Davies, 2004). Because there is a shared precursor pool of GGPP, manipulation of one of the branch pathways can have significant effects on the flux through other branches (Davies, 2004). Thus, upand downregulation of phytoene synthase $(P S Y)$ to increase and decrease carotenoid biosynthesis causes reciprocal changes in GA levels (Fray et al., 1995). Therefore, it is reasonable to suspect that there might be a key step involved in finely controlling the shift from ABA to GAs biosynthesis, or vice versa, which leads to the difference in GA and ABA levels between the two cultivars during fruit development.

Although the changes in GA and ABA levels in fruit during development have been quantified, fundamental questions about their mode of action in fruit have not been answered. The fact that a single application of GA induces not only fruit set but also the complete development of the fruit suggest that GA acts as a trigger of the entire developmental process. In the future, clarifying the exact roles of bioactive GAs and ABA, and their interaction with other hormones should be very useful for understanding the roles of hormones during fruit growth and the production of high-quality fruit in japanese pear.

\section{Literature Cited}

Asahina, M., H. Iwai, A. Kikuchi, S. Yamaguchi, Y. Kamiya, H. Kamada, and S. Satoh. 2002. Gibberellin produced in the cotyledon is required for cell division during tissue reunion in the cortex of cut cucumber and tomato hypocotyls. Plant Physiol. 129:201-210.

Barendse, G.W.M., A.J. Rodrigues-Pereira, P.A. Berkers, F.M. Driessen, A. van Eyden-Emons, and H.F. Linskens. 1970. Growth hormones in pollen, styles and ovaries of Petunia hybrida and Lilium species. Acta Bot. Neerlandica 19:175-186.

Ben-Cheikh, H., J. Perez-Botella, F.R. Tadeo, and E. Primo-Millo. 1997. Pollination increases gibberellin levels in developing ovaries of seeded varieties of citrus. Plant Physiol. 114:557-564.

Crane, J.C. 1964. Growth substances in fruit setting and development. Annu. Rev. Plant Physiol. 15:303-326.

Davies, P.J. (ed.). 2004. Plant hormones: Biosynthesis, signal transduction, action! Kluwer Academic Publishers, Dordrecht, the Netherlands.

Fray, R.G., A. Wallace, P.D. Fraser, D. Valero, P. Hedden, P.M. Bramley, and D. Grierson. 1995. Constitutive expression of a fruit phytoene synthase gene in transgenic tomatoes causes dwarfism by redirecting metabolites from the gibberellin pathway. Plant $\mathrm{J}$. 8:693-701.

Garcia-Martinez, J.L. and P. Hedden. 1997. Gibberellins and fruit development, p. 263-285. In: F.A. Tomas-Barberan, and R.J. Robins (eds.). Phytochemistry of fruit and vegetables. Oxford Science Publications, Heidelberg, Germany.

Gillaspy, G., H. David, and W. Gruissem. 1993. Fruits: A developmental perspective. Plant Cell 5:1439-1451.

Goto, N. and R.P. Pharis. 1999. Role of gibberellins in the development of floral organs of gibberellin-deficient mutant, ga1-1, of Arabidopsis thaliana. Can. J. Bot. 77:944-954.

Hayashi, S. and K. Tanabe. 1991. Basic knowledge of fruit tree culture [in Japanese]. Agriculture Association Press, Tottori, Japan.

Hedden, P. and G.V. Hoad. 1985. Hormonal regulation of fruit growth and development. Brit. Plant Growth Regulat. Group Monogr. 12: 211-225.

Hedden, P. and A.L. Phillips. 2000. Gibberellin metabolism: New insights revealed by the genes. Trends Plant Sci. 5:523-530.

Herrero, M. and M. Gascon. 1987. Prolongation of embryo sac viability in pear (Pyrus communis) following pollination or treatment with gibberellic acid. Ann. Bot. (Lond.) 60:287-293. 
Hisatomi, T. 2003. Cloning and expression of the genes related to GA biosynthesis and signal transduction in Pyrus genus [in Japanese]. Tottori University, Tottori, Japan, MS thesis.

Mander, L.N., D.J. Owen, S.J. Croker, P. Gaskin, P. Hedden, M.J. Lewis, M. Talon, D.A. Gage, J.A. Zeevaart, M.L. Brenner, and C. Cheng. 1996. Identification of three C20-gibberellins: $\mathrm{GA}_{97}$ (2 betahydroxy-GA $\left.\mathrm{G}_{53}\right), \mathrm{GA}_{98}\left(2\right.$ beta-hydroxy- $\left.\mathrm{GA}_{44}\right)$ and $\mathrm{GA}_{99}$ ( 2 betahydroxy-GA 19 ). Phytochemistry 43:23-28.

Morris, R.O. 1997. Hormonal regulation of seed development, p. 117 148. In: B.A. Larkins, and I.K. Vasil (eds.). Cellular and molecular biology of plant seed development. Kluwer Academic Publishers, Dordrecht, the Netherlands.

Nakagawa, S., I. Kiyokawa, H. Matsui, and H. Kurooka. 1973. Fruit development of peach and japanese pear as affected by destruction of the embryo and application of gibberellins. J. Jpn. Soc. Hort. Sci. 37:104-112.

Nakagawa, S., H. Matsui, E. Yuda, N. Murofushi, and N. Takahashi. 1979. Biologically active gibberellins in immature seeds of Pyrus serotina. Phytochemistry 18:1695-1697.

Nester, J.E. and J.A.D. Zeevaart. 1988. Flower development in normal tomato and a gibberellin-deficient ( $\mathrm{ga}$-2) mutant. Amer. J. Bot. 75:45-55. Nishijima, T. and N. Katsura. 1989. A modified micro-drop bioassay using dwarf rice for detection of femtomol quantities of gibberellins. Plant Cell Physiol. 30:623-627.

Ozga, J. and M. Dennis. 2003. Hormonal interactions in fruit development. J Plant Growth Regulat. 22:73-81.

Pharis, R.P. and R.W. King. 1985. Gibberellins and reproductive development in seed plants. Annu. Rev. Plant Physiol. 36:517-568. Singh, D.P., A.M. Jermakow, and S.M. Swain. 2002. Gibberellins are required for seed development and pollen tube growth in Arabidopsis. Plant Cell 14:3133-3147.

Sponel, V.M. and P. Hedden. 2004. Gibberellin biosynthesis and inactivation, p. 63-94. In: P.J. Davies (ed.). Plant hormones: Biosynthesis, signal transduction, action! Kluwer Academic Publishers, Dordrecht, the Netherlands.

Swain, S.M., J.B. Reid, and Y. Kamiya. 1997. Gibberellins are required for embryo and seed development in pea. Plant J. 12: 1329-1338.
Talon, M., L. Zacrias, and E. Primo-Millo. 1990. Hormonal changes associated with fruit set and development in mandarins differing in their parthenocarpic ability. Physiol. Plant. 79:400-406.

Weiss, D., A. Izhaki, G. Ben-Nissan, Y. Dagan, and A. Borochov. 1997. GA-induced gene expression in Petunia flower. Plant Physiol. 114:S160 (abstr.).

Yang, J., J. Zhang, Z. Wang, and Q. Zhu. 2003. Hormones in the grains in relation to sink strength and postanthesis development of spikelets in rice. Plant Growth Regulat. 41:185-195.

Yuda, E., M. Hirakawa, I. Yamaguchi, N. Murofushi, and N. Takahashi. 1983. Fruit set and development of three pear species induced by gibberellins. Acta Hort. 137:277-284.

Yuda, E., H. Matsui, S. Nakagawa, M. Yukimoto, and K. Wada. 1984. Effect of 15- $\beta-\mathrm{OH}$ gibberellins on the fruit set and development of three pear species. J. Jpn. Soc. Hort. Sci. 53:235-241.

Yuda, E., S. Nakagawa, H. Matsui, K. Wada, and T. Imai. 1981. The effect of $15-\beta-\mathrm{OH}$ gibberellins on the fruit set and development of pears. HortScience 16:436 (abstr.).

Zhang, C., K. Tanabe, F. Tamura, A. Itai, and S. Wang. 2005a. Partitioning of ${ }^{13} \mathrm{C}$-photosynthate from spur leaves during fruit growth of three japanese pear (Pyrus pyrifolia) cultivars differing in maturation date. Ann. Bot. (Lond.) 95:685-693.

Zhang, C., K. Tanabe, F. Tamura, A. Itai, and S. Wang. 2005b. Spur characteristics, fruit growth and carbon partitioning in two latematuring japanese pear (Pyrus pyrifolia) cultivars with contrasting fruit size. J. Amer. Soc. Hort. Sci. 130:252-260.

Zhang, C., K. Tanabe, F. Tamura, K. Matsumoto, and A. Yoshida. $2005 \mathrm{c} .{ }^{13} \mathrm{C}$-photosynthate accumulation in japanese pear fruit during the period of rapid fruit growth is limited by the sink strength of fruit rather than by the transport capacity of the pedicel. J. Expt. Bot. $56: 2713-2719$.

Zhang, C., K. Tanabe, S. Wang, F. Tamura, A. Yoshida, and K. Matsumoto. 2006. The impact of cell division and cell enlargement on the evolution of fruit size in Pyrus pyrifolia. Ann. Bot. (Lond.) 98:537-543.

Zhang, C., K. Tanabe, F. Tamura, A. Itai, and M. Yoshida. 2007. Role of gibberellins in increasing sink demand in japanese pear fruit during rapid fruit growth. Plant Growth Regulat. 52:161-172. 